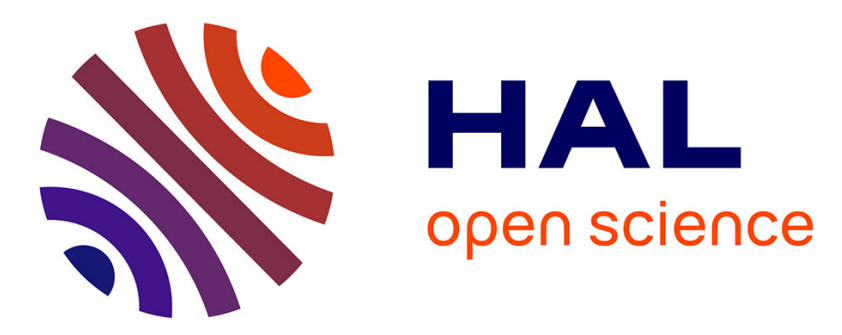

\title{
Servitization of Biomass Processing for a Virtual Biorefinery: Application to the Lignocellulosic Biomass in a French Local Territory
}

Michelle Houngbé, Anne-Marie Barthe-Delanoë, Stéphane Négny

\section{- To cite this version:}

Michelle Houngbé, Anne-Marie Barthe-Delanoë, Stéphane Négny. Servitization of Biomass Processing for a Virtual Biorefinery: Application to the Lignocellulosic Biomass in a French Local Territory. 20th Working Conference on Virtual Enterprises (PRO-VE), Sep 2019, Turin, Italy. pp.477-486, 10.1007/978-3-030-28464-0_41. hal-02478754

\author{
HAL Id: hal-02478754 \\ https://hal.inria.fr/hal-02478754
}

Submitted on 14 Feb 2020

HAL is a multi-disciplinary open access archive for the deposit and dissemination of scientific research documents, whether they are published or not. The documents may come from teaching and research institutions in France or abroad, or from public or private research centers.
L'archive ouverte pluridisciplinaire HAL, est destinée au dépôt et à la diffusion de documents scientifiques de niveau recherche, publiés ou non, émanant des établissements d'enseignement et de recherche français ou étrangers, des laboratoires publics ou privés.

\section{(ㄷ)(1)}

Distributed under a Creative Commons Attribution| 4.0 International License 


\title{
Servitization of Biomass Processing for a Virtual Biorefinery: Application to the Lignocellulosic Biomass in a French Local Territory
}

\author{
Michelle Houngbé, Anne-Marie Barthe-Delanoë, Stéphane Négny \\ ${ }^{1}$ Laboratoire de Génie Chimique, Université de Toulouse,CNRS, INPT, UPS, \\ Toulouse, France \\ michelle.houngbe@inp-toulouse.fr, \{annemarie.barthe, stephane.negny\}@ensiacet.fr
}

\begin{abstract}
Processing biomass requires four major steps (pretreatment, fermentation, separation and purification) achieved by dedicated plants called biorefineries. These highly specialized structures cannot cope with the high variability of the whole biomass supply chain. Thus, providing agility to biorefineries is a key challenge to foster biomass processing. The goal is to design a virtual biorefinery as a collective network supported by the servitization of unit operations and the reuse of existing devices. In this regard, the first step described in this paper aims to gather and organize knowledge about a given local area (stakeholders, services) and the existing transformation process operations (inputs, outputs) through a framework. To this end, two metamodels are proposed: one to collect and structure the required information about the local area; one to organize the knowledge about the transformation processes. Their use is illustrated by a use case provided by a municipalities community located in South-West France.
\end{abstract}

Keywords: Servitization, Biomass, Collaborative network modeling, Collaborative process, Industry 4.0 .

\section{Introduction}

Biomass requires dedicated transformation processes, depending on the biomass type, quality, purity (and even quantity) and also on the targeted bioproduct. These processes operate under high-specialized conditions, where each process step requires specific equipment (specific operating methods and specific unit operations). At the plant level, biorefineries are standalone plants dedicated to a specific biomass transformation process. Thus, biorefineries are not able to face the variabilities regarding supply and demand as well as the biomass variety. The challenge, as underlined in [1], is to bring agility to the biorefinery system to foster biomass processing.

In this sense, the research works presented in [2] aim to decentralize the biomass process through a virtual biorefinery. The virtual biorefinery concept lies on the shortterm collaboration of different stakeholders, each one achieving one or several steps of 
the transformation process. This collaboration enables low coupling among the process steps in order to adapt the biomass processing when a change occurs (supply, demand etc.). Besides, leaning on the reuse of existing equipment and/or plants would avoid investments into physical structures dedicated to a given process. To achieve this goal, a servitization framework is required to help the stakeholders to describe their activities with a product-service strategy. This paper focus on the developed approach to support the servitization of the stakeholders involved into this collaborative biomass processing.

The paper is structured as follows: the next section highlights the state of art of servitization for biorefineries. Section 3 describes our proposal to support the servitization of biomass processing stakeholders (farmers, chemical plants, etc.). Section 4 illustrates the proposed servitization framework with a use case provided by a municipalities community located in South-West France, before addressing the further work to be done and concluding.

\section{State of the Art of Servitization in Biorefineries}

The servitization concept emerged in the late 1980's under an uncertain industrial context marked by: a strong competition between companies in the global market place; a raise of product customization to satisfy customers changeable needs; the constant evolution of technologies. Since its first definition as "bundles' consisting of customerfocused combinations of goods, services, support, self-service, and knowledge" [3], it has been a growing interest for this topic, for the researchers and the industrials [4]. By adding different levels of services such as base (spare parts), intermediate (maintenance, training) and advanced (contract) to an initial physical product, servitization affects the whole industry from the marketing department to the production workshop.

The description of the actors' services is part of a Product-Service System (PSS) strategy. As a servitization specification, the PSS differs by taking into consideration the life cycle of the integrated product and service offering. [5] classifies the PSSs into eight categories according to four main dimensions: market value for the user, costs for the provider, capital needs, and ability to sustain value in the future. Based on this classification, the agile biorefinery tends to be close to the result-oriented category of PSSs (within the functional result subcategory). Indeed, this is the capability (the capabilities) (i.e. one or more services) proposed by each actor into the collaboration that is (are) involved to fulfill one (or more) step(s) of the biomass transformation according to the targeted objective. However, the PSS was determined for the manufacturing sector by focusing how the company creates added value. In this approach, the transformation process of the matter with all its constraints is not taken into account. Therefore, it has to be adapted in the context of a biorefinery.

As mentioned earlier, this paper focuses on the servitization to support the collaboration which is the core concept of the virtual biorefinery. Regarding the domain of virtual enterprises, that are defined by [6] as "temporary consortium of enterprises that join skills and resources, supported by computer networks, to better respond to a business opportunity", they lean on existing frameworks to implement servitization. 
[7]'s studies have developed a methodology based on Model Driven Service, which is based on Model Driven Engineering, that contains all the phases of the service life cycle (requirements, design, testing and implementation). This approach aims to support the shift from a production focused on the product towards a production focused on a service-oriented strategy for virtual manufacturing environment. Besides, [8] propose a framework organized along three dimensions: extended product, service typology and service innovation organization. Combined together, they help companies to determine their servitization position. This framework was tested in several companies, which want to move towards the service-oriented virtual enterprise: a machine tool manufacturer, a TV manufacturer and a clothing manufacturer. These frameworks apply particularly to manufacturing companies.

Regarding the chemical industry, there are fewer examples of servitization compared to the manufacturing domain. But it is important to note that the ongoing trend in the chemical industry area is to shift from a high volume in mass production towards custom products. This customization trend changes the companies' business models to more innovative ones. [9] show that three types of business models encourage servitization in chemical industries. Chemical Product Services (CPS) gives priority to the sale/use of chemical product-service bundles. Chemical Management Services (CMS) leans on long-term contract policy between customers and suppliers. For instance, PPG, a company specialized in wastewater treatment, is paid according to the amount of cleaned water. Chemical Leasing makes available chemicals for service and ensure their maintenance instead of selling them. Among these three business models promoting servitization, the most widespread is CMS [9] .

It is interesting to underline that in the literature related to this business area, servitization is studied from the company strategy point of view (macro scale). There is a lack of framework to support and guide servitization of the transformation process (meso scale), especially for biomass transformation process. The next section presents a proposal of such a framework.

\section{A Framework to Support Servitization of Biomass Transformation Processes}

\subsection{Collaborative Situation Characterization}

The first step is to define the collaborative situation: stakeholders, targeted bioproduct, available biomass, etc. To this end, a meta-model structuring the knowledge is necessary, as detailed in [2]. This meta-model dedicated to the biorefinery is based on the CORE meta-model [10]. This meta-model is structured around four families of concepts: the context (the environment of the collaboration), the actors (the partners of collaboration), the objectives (the purpose of the collaboration) and the performance (assessment of the collaboration based on Key Performance Indicators). An enhanced version of the concepts of the first version of the virtual biorefinery meta-model is proposed here (Figure 1). 
In the context package, the deposit concept is crucial. It complies with a sector logic as wood sector, agricultural sector, etc. It takes into account the biomass which is characterized by its intrinsic physical and biochemical properties, by a seasonality and by a crop rotation. Besides, the geographical area where the deposit is located has a specific pedology, topography and climate where a type of production (intensive, extensive, organic) is realized. Finally, the deposit concept integrates the goods concept that includes the roadways to access to the deposit. Finally, people and institutions concerned by its exploitation are also considered.

In the objective package, the biomass processing is the main goal to reach. It produces bioproducts and have to meet market opportunities. However, impact factors about technology, finance, society or environment can affect positively or negatively the main goal.

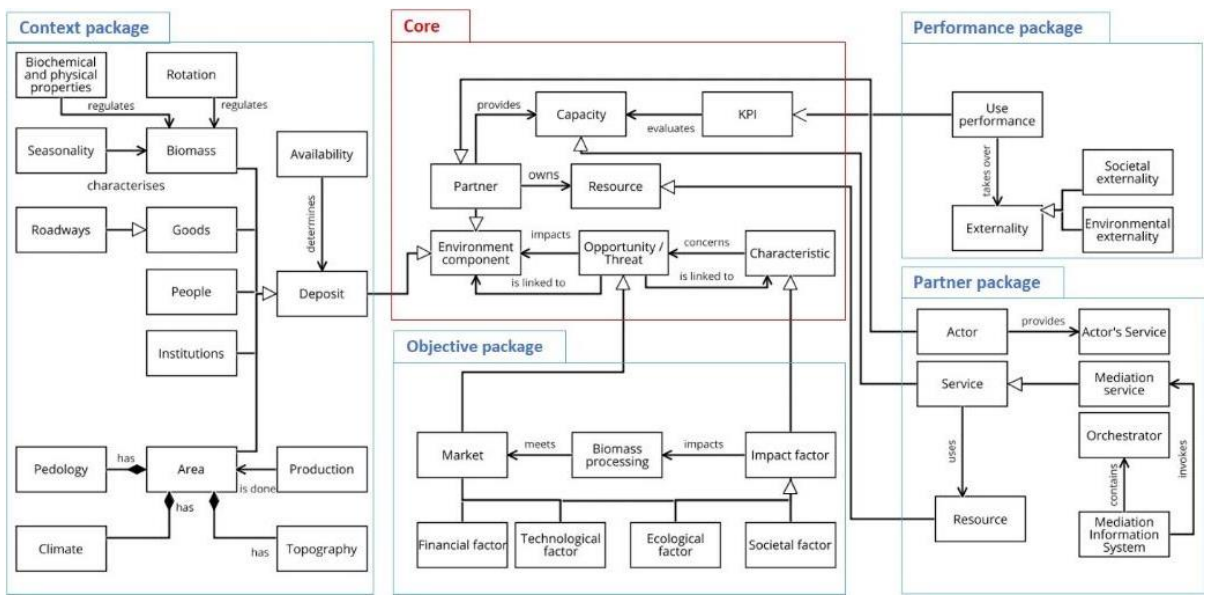

Fig. 1. Meta-model of collaborative situation for the virtual biorefinery.

In the partner package, each stakeholder of the collaboration is called an actor. She/he provides one or several services that requires resources. The whole collaboration is orchestrated by a Mediation Information System (MIS).

The performance package consists on assessing the collaboration, thanks to Key Performance Indicators (KPI). Relevant KPI lean for instance on the sale of use performance for each actor and the overall performance. The services generate externalities, positive or negative for the environment (e.g. pollution, reforestation) and the society (e.g. job creation, economic decline).

Thus, the meta-model contains concepts about the whole collaborative situation. The instantiation of the meta-model into a model is made with data about the stakeholders, the availability of biomass on the studied territory or the targeted bioproduct, etc. All of these data can be gathered either manually or automatically. Indeed, in the area of Agriculture 4.0, the amount of emitted data regarding farms, weather conditions, crops, etc. is exploding. Based on these data, information regarding (for example) the biomass valorization opportunities can be inferred based on weather conditions, etc. to feed the model of the virtual biorefinery. 
This gathered knowledge about the collaborative situation is essential to define the collaborative transformation process, that will be performed by the virtual biorefinery. Nevertheless, additional knowledge is required in order to choose the relevant transformation process (from a chemical point of view), given the biomass characteristics and the bioproduct identified through the virtual biorefinery model.

\subsection{Biomass Processing Knowledge Organization}

The second step of this servitization framework aims to structure the knowledge required to identify the chemical process involved into the biomass processing.

Lignocellulosic biomass processing can be seen as a four major step process: (i) pretreatment; (ii) conversion; (iii) separation; (iv) purification. Biomass pre-treatment is crucial for the next process phases. Indeed, in this step the structure of the biomass is modified to make sugar accessible from lignin, cellulose and hemicellulose. The next phase is the biomass conversion into building blocks (C2 to C6 sugars). It can be achieved in different ways: chemical, bio chemical, thermochemical. These building blocks are the bases to design bioproducts, bioenergy and biofuel. Finally, separation and purification refine the output to fit with the customer's requirements. Each major step is composed of sub-process or unit operations which are specified according to the input biomass characteristics and the targeted bioproducts.

Given this background, the minimal required knowledge about the chemical process is, for each major step (respectively each sub-process or unit-operation): input (biomass, intermediate products; output (intermediate product, final product); operating conditions. As there is no knowledge base organizing the knowledge about existing processes for biomass transformation at the required level of abstraction, an additional meta-model is proposed to this end, based on the SADT-IDFE0 diagram notation. SADT-IDEF0 offers a degree of details which is relevant regarding the abovementioned needs. An example of such a model is detailed in Section 4.3.

This knowledge base can also embed additional knowledge regarding the matching between the services proposed by the actors and the required process steps (subprocess, unit operation), as Montarnal et al. [11] propose in their research work regarding the manufacturing industries. Each process, sub-process and unit operation is therefore seen as an objective that an actor service (or a set of actors' services) will fulfill. This way, the required knowledge about services is structured and ready to be used to deduce a relevant collaborative transformation process.

\section{Case Study}

\subsection{Case Study Presentation}

Two municipalities communities from the French department of the Landes (Communauté de Communes Coeur Haute Lande, and Communauté de Communes de Mimizan) look for solutions to recycle green waste. The lignocellulosic biomass is 
abundant and diversified within their territory. The characterization of these two local territories using the presented framework will support the identification of the existing stakeholders and of their related services to meet these opportunities to valorize local biomass. Besides, this knowledge will also be used to design the collaborative process treatment, performed by the virtual biorefinery.

\subsection{Instantiation of the Metamodel for Collaborative Situation}

To instantiate the metamodel, stakeholders able to play a role in the biomass processing were identified. Then, semi-directive interviews were organized according to an interview guide. These interviews focused on the following topics: business environment, role in green waste processing, existing or possible partnership with a company inside or outside the territory, positive impact of the activity (for the stakeholder, for the territory). The objective is to understand the environment in which these actors of the biomass area evolve. These interviews also helped to determine the existing constraints.

\subsubsection{Instantiation of the Context Package}

The instantiation of the context (Figure 2) reveals that on these local territories the green waste deposit involves two parts of green waste: woody and non-woody. Each of them owns a specific density, humidity and seasonality.

About 15,000 tons of green waste are available in these territories. Different institutions (cities, local authorities, consular organizations) are involved in this recycling initiative as well as the citizen association "SAS Energie Citoyenne Haute Lande".

\subsubsection{Instantiation of the Partner Package}

Different types of actor (public entity, farmer, environment service provider) are able to provide services to perform a step of the transformation process. The instantiation of the partner concept shows that a process activity can be realized by different actors, such as the composting step that can be performed by the Communaute de Communes Coeur Haute Lande, Mimizan, VEOLIA or RTE (Electricity Transmission Network) (Figure 3) or such as the shearing (performed by citizens or the local authority).

Resource used by the actor will differentiate the actor's service. But it will be necessary to define functional and non-functional requirement (price, delay, reputation) to sort services in case of competition. 


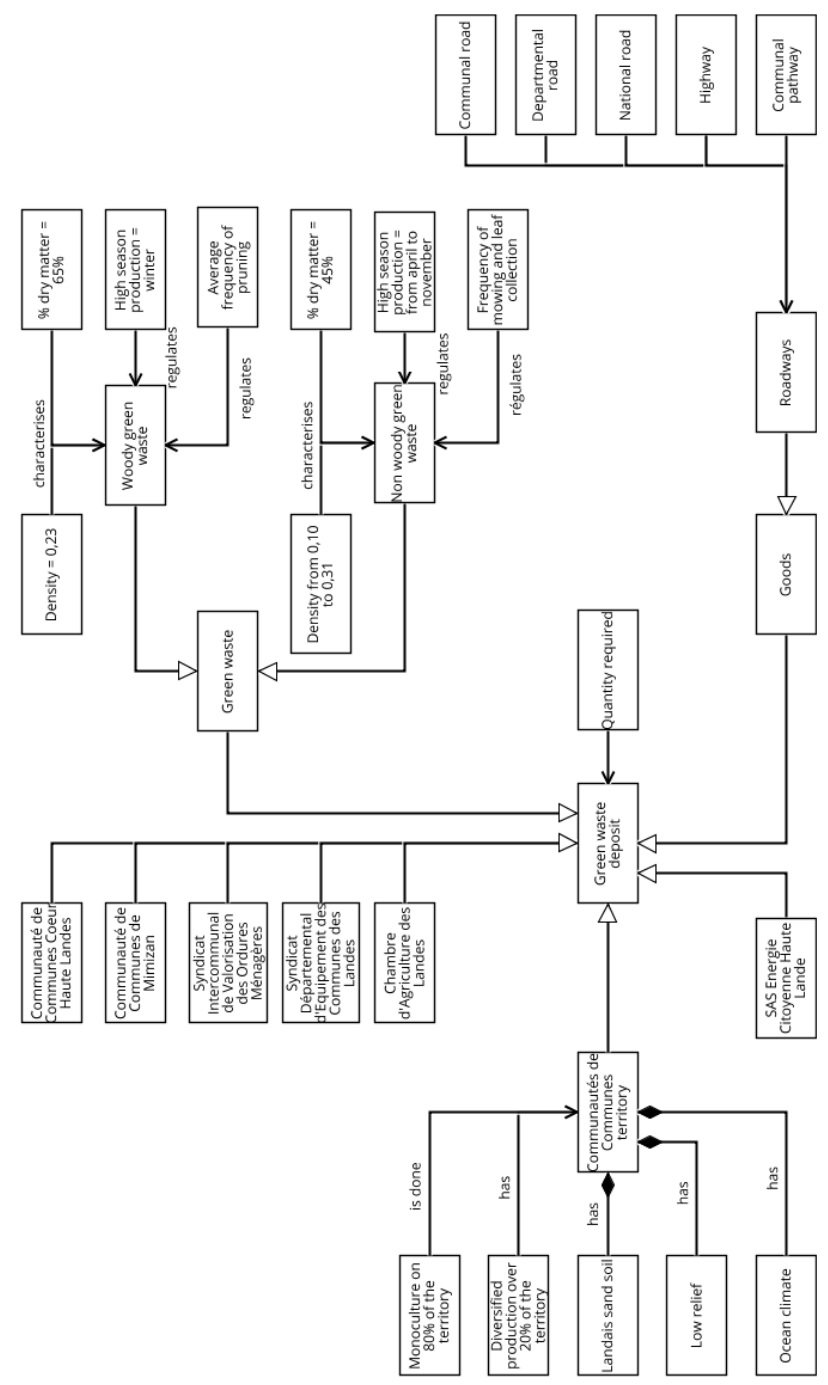

Fig. 2. Instantiation of the context package.

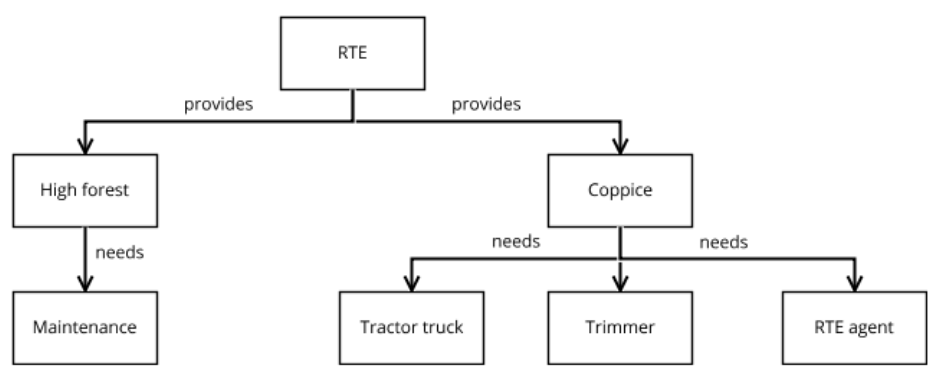

Fig. 3. Instantiation of the partner package: example of the RTE actor. 


\subsubsection{Instantiation of the Objective Package}

Regarding the instantiation of the objective package concepts, Figure 4 highlights that the main objective 'composting biomass' meets different opportunities, which represents sub-objectives. The main objective (i.e. the targeted bioproduct) is "biogas fuel" and "standard compost". In this study case, the identified impact factors have a positive impact on the collaboration objective.

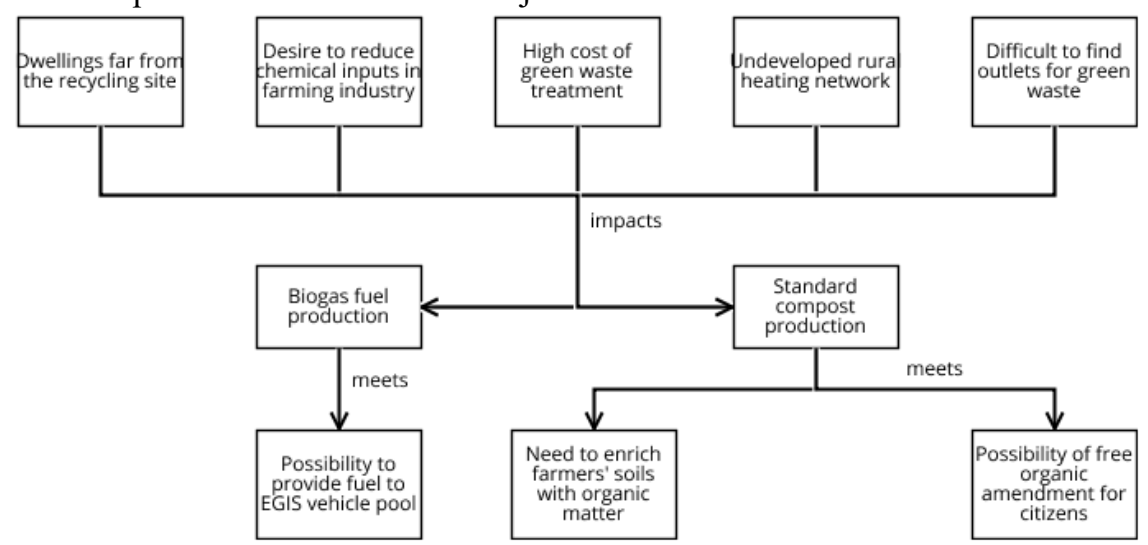

Fig. 4. Instantiation of the objective package.

\subsubsection{Instantiation of the Performance Package}

The performance to be reached by some stakeholders as the SIVOM (Figure 5) and the farmers is determined by contract. These services generate positive externalities as job creation (the creation of a new job for compost quality control), or additional revenues linked to the compost sale.

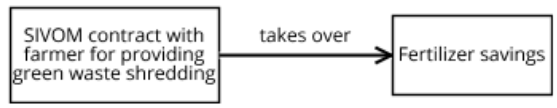

Fig. 5. Instantiation of the performance package: example of the SIVOM contract.

\subsection{Knowledge Base for Chemical Process Involved in the Composting Processing}

In addition to the model representing the knowledge about the collaborative situation, it is now necessary to collect and organize additional knowledge about the composting process and the matching services. To gather knowledge about the generic composting process, we leaned on dedicated handbooks, such as [12]. The model obtained in the Figure 6 represents both the composting process as (sub-)objectives, and the proposed actors' services matching these (sub-)objectives. 


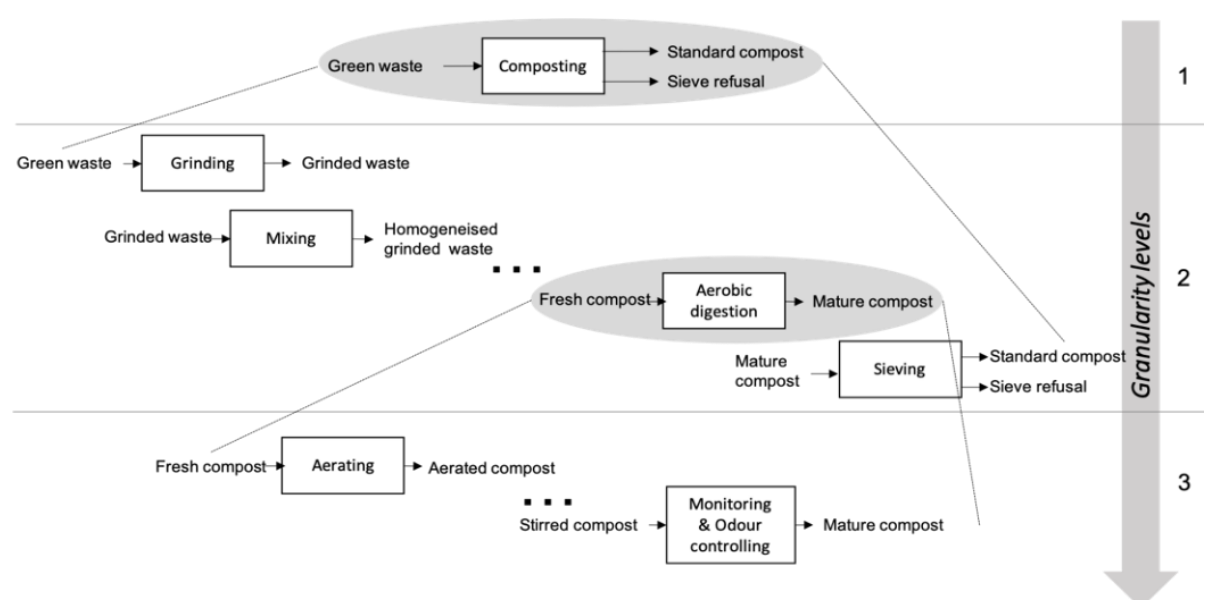

Fig. 6. Composting process description using a SADT-IDEF0 inspired meta-model.

\section{Perspectives and Conclusion}

Biomass processing is subject to several constraints to the structural level (i.e. biorefinery) and to the process level generating high variability in biomass supply and bioproduct production. This is the reason why it is necessary to bring agility to the entire system in order to improve the biomass transformation process. In this perspective, the "virtual biorefinery" concept enables the collaboration between the stakeholders of the biomass processing. It is based on services provided by the actors to fulfill one or more steps of the process biomass treatment. Thus, this paper presents a servitization framework composed by two meta-models. The first meta-model aims to characterize and structure the knowledge about the collaborative situation according to the environment, the partners, the objective(s) and the performance, with data collected manually or with sensors. It is coupled with a second meta-model to structure the additional knowledge about the biomass transformation processes. As presented in the case study, the instantiation of these two meta-models provides the necessary knowledge to establish a collaborative biomass transformation process. On a short-term perspective, the next step of these works is to choose and implement the algorithm to design the collaborative transformation process. The competition among several services fulfilling the same objective has to be considered: the use of functional and non-functional criteria may provide a way to choose the most relevant option.

Acknowledgments. These research works are funded by the French Research Agency (ANR) regarding the research project ARBRE [Grant number ANR-17-CE10-0006], 2017-2021. The authors would like to thank the project partners for their advice and comments regarding this work. 


\section{References}

[1] European Commission, Innovating for Sustainable Growth - A bioeconomy for Europe., Publications Office of the European Union. Luxembourg, 2012.

[2] M. Houngbé, A.-M. Barthe-Delanoë, and S. Négny, 'Towards Virtual Biorefineries', in Collaborative Networks of Cognitive Systems - 19th IFIP WG 5.5 Working Conference on Virtual Enterprises, PRO-VE 2018, Cardiff, UK, September 17-19, 2018, Proceedings, 2018, vol. 534, pp. 571-580.

[3] S. Vandermerwe and J. Rada, 'Servitization of business: Adding value by adding services', European Management Journal, vol. 6, no. 4, pp. 314-324, 1988.

[4] T. Baines, A. Ziaee Bigdeli, O. F. Bustinza, V. G. Shi, J. Baldwin, and K. Ridgway, 'Servitization: revisiting the state-of-the-art and research priorities', International Journal of Operations \& Production Management, vol. 37, no. 2, pp. 256-278, Feb. 2017.

[5] A. Tukker, 'Eight types of product-service system: eight ways to sustainability? Experiences from SusProNet', Business Strategy and the Environment, vol. 13, no. 4, pp. 246-260, Jul. 2004.

[6] L. M. Camarinha-Matos and H. Afsarmanesh, 'Collaborative networks: a new scientific discipline', J Intell Manuf, vol. 16, no. 4-5, pp. 439-452, Oct. 2005.

[7] Y. Ducq, D. Chen, and T. Alix, 'Principles of Servitization and Definition of an Architecture for Model Driven Service System Engineering', in Enterprise Interoperability, vol. 122, M. van Sinderen, P. Johnson, X. Xu, and G. Doumeingts, Eds. Berlin, Heidelberg: Springer Berlin Heidelberg, 2012, pp. $117-128$.

[8] D. Chen and S. Cusmeroli, 'Framework for manufacturing servitization in virtual enterprise environment and ecosystem', IFAC-PapersOnLine, vol. 48, no. 3, pp. 2244-2249, 2015.

[9] D. Buschak and G. Lay, 'Chemical industry: Servitization in niches', in Servitization in industry, Springer, 2014, pp. 131-150.

[10] F. Bénaben, M. Lauras, S. Truptil, and N. Salatgé, 'A Metamodel for Knowledge Management in Crisis Management', in Proceedings of the 49th Hawaii International Conference on System Sciences (HICSS 2016), 2016, pp. 126-135.

[11] A. Montarnal, W. Mu, F. Benaben, J. Lamothe, M. Lauras, and N. Salatge, 'Automated deduction of cross-organizational collaborative business processes', Information Sciences, vol. 453, pp. 30-49, Jul. 2018.

[12] Northeast Regional Agricultural Engineering Service., G. B. Willson, Maarten. Van de Kamp, and Robert. Rynk, On-Farm Composting Handbook. 1992. 